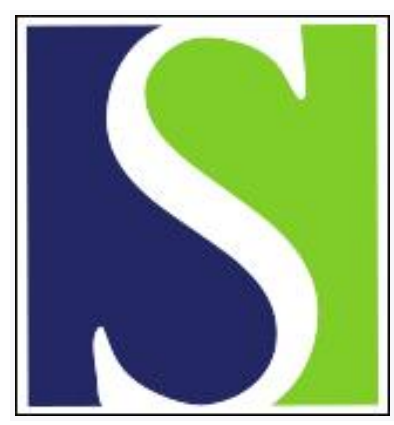

Scand J Work Environ Health 2002;28(5):324-327

https://doi.org/10.5271/sjweh.681

Issue date: Oct 2002

Frequency dependence of hand-arm vibration on palmar sweating response

by Ando $H$, Noguchi $R$, Ishitake $T$

Affiliation: Department of Environmental Medicine, Kurume University School of Medicine, 67, Asahi-machi, Kurume, 830-0011, Japan.hando@med.kurume-u.ac.jp

Refers to the following text of the Journal: $1999 ; 25(3): 278-284$

The following article refers to this text: $2003 ; 29(3): 216-219$

Key terms: acute vibration stress; frequency dependence; hand-arm vibration; palmar sweating response; somatosympathetic reflex; vibration frequency

This article in PubMed: www.ncbi.nlm.nih.gov/pubmed/12432985 


\title{
Frequency dependence of hand-arm vibration on palmar sweating response
}

\author{
by Hideo Ando, MD, ${ }^{1}$ Ryo Noguchi, MD, ${ }^{1}$ Tatsuya Ishitake, $M D^{1}$
}

\begin{abstract}
Ando $\mathrm{H}$, Noguchi $\mathrm{R}$, Ishitake $\mathrm{T}$. Frequency dependence of hand-arm vibration on palmar sweating response. Scand J Work Environ Health 2002;28(5):324-327.

Objectives This study attempted to elucidate the effects of hand-arm vibration frequency on palmar sweating response.

Methods Palmar sweating was measured before and during vibration exposure on the right palm of six healthy men. The left hand was exposed for 3 minutes to the following root mean square (rms) acceleration magnitudes and frequencies of vibration: $5 \mathrm{~m} / \mathrm{s}^{2}$ at $31.5 \mathrm{~Hz}, 10 \mathrm{~m} / \mathrm{s}^{2}$ at $63 \mathrm{~Hz}, 20 \mathrm{~m} / \mathrm{s}^{2}$ at $125 \mathrm{~Hz}, 40 \mathrm{~m} / \mathrm{s}^{2}$ at $250 \mathrm{~Hz}$, and $50 \mathrm{~m} / \mathrm{s}^{2}$ at $315 \mathrm{~Hz}$. According to international standard ISO 5349, these vibration levels generate the same frequency-weighted acceleration magnitude of $2.5 \mathrm{~m} / \mathrm{s}^{2} \mathrm{rms}$. A control condition consisted of grasping a handle without vibration. As the index of the activated central nervous system, plasma 3-methoxy-4-hydroxyphenylglycol (MHPG) was measured before and immediately after each vibration exposure.

Results Each condition of vibration induced a palmar sweating response. Among the six vibration conditions, vibration of $125 \mathrm{~Hz}$ and $63 \mathrm{~Hz}$ caused large palmar sweating responses compared with those of $315 \mathrm{~Hz}$ and the control condition. Plasma MHPG did not increase significantly after either vibration exposure.

Conclusions The palmar sweating response to vibration with the same frequency-weighted acceleration magnitude suggested dependency on frequency. The study suggests that the somatosympathetic reflex is associated with different palmar sweating responses.
\end{abstract}

Key terms acute vibration stress, palmar sweating, somatosympathetic reflex, vibration frequency.

Acute exposure to hand-arm vibration is known to induce some physiological changes, such as vasoconstriction and palmar sweating, through the sympathetic nervous system $(1,2)$. As far as vasoconstriction is concerned, many studies have revealed that the response depends upon both the intensity and frequency of vibration $(3,4)$. To date, on the other hand, few studies have been conducted on the effects of exposure to handarm vibration on palmar sweating response.

In an earlier experimental study, we found that the higher the vibration intensity, the larger the palmar sweating response to vibration stress (5). The aim of our present study was to elucidate the effects of vibration frequency on palmar sweating response.

\section{Subjects and methods}

\section{Subjects}

Six healthy male volunteers, all of whom were 20 years of age, participated in the study. None of them had previously experienced any significant exposure to handarm vibration. One of them was a smoker who was requested to refrain from smoking for at least 2 hours before the test. None of the subjects were allowed to make conversation, sleep, or change position often during the experiment. All the subjects wore a vest, underpants, shirt, trousers, and socks throughout the series of experiments. The estimated clo (resistance of clothing

Reprint requests to: Dr Hideo Ando, Department of Environmental Medicine, Kurume University School of Medicine, 67, Asahi-machi, Kurume, 830-0011, Japan. [E-mail: hando@med.kurume-u.ac.jp] 
against dry heat loss) varied from 0.7 to 0.8 . Written informed consent was obtained from all the subjects before they started the experiment.

\section{Measurements}

Palmar sweating was measured by the ventilated capsule method (Hidrograph; AMU-100, Kands, Kariya, Japan). A capsule of $1 \mathrm{~cm}^{2}$ in size was mounted on the right palm, which was not exposed to vibration. Dry nitrogen gas was pumped into the capsule at a rate of 0.3 $1 / \mathrm{min}$ at one side, and the gas exited from the other side after being moistened by the sweat. The sweating volume was estimated from the change in humidity inside the capsule.

As an index of an activated central nervous system, including the hypothalamus, the plasma 3-methoxy-4hydroxyphenylglycol (MHPG) concentration was assessed from 5 milliliters of venous blood (6).

\section{Experimental procedure}

A series of experiments was performed in a soundproof room with a constant temperature of $22^{\circ} \mathrm{C}$ and a relative humidity of $60 \%$. So that adverse reactions to vibration would be excluded, each subject experienced all the vibration frequencies used in the study several times before the experiment was started.

After resting in the waiting room for 20 minutes, the subject entered the experimental room. A blood sample for MHPG was obtained from the right arm after a 30minute period of acclimatization. The sampling was followed by the commencement of continuous recording of palmar sweating. After the stability of the palmar sweating was established, for at least 5 minutes, the subject was asked to grasp the handle of a vibration generator with his left hand for 3 minutes. Sinusoidal vibration was produced in the vertical direction by an electrodynamic vibrator (Akashi ASE-12, Yokohama, Japan). Visual feedback through a digital dynamometer allowed the subject to keep a constant grasp at a power of $49 \mathrm{~N}$. Immediately after the vibration exposure, another blood sample was obtained.

The sinusoidal vibration applied to the subject included $5 \mathrm{~m} / \mathrm{s}^{2} \mathrm{rms}$ (root-mean-square) at $31.5 \mathrm{~Hz}, 10$ $\mathrm{m} / \mathrm{s}^{2} \mathrm{rms}$ at $63 \mathrm{~Hz}, 20 \mathrm{~m} / \mathrm{s}^{2} \mathrm{rms}$ at $125,40 \mathrm{~m} / \mathrm{s}^{2} \mathrm{rms}$ at $250 \mathrm{~Hz}$, and $50 \mathrm{~m} / \mathrm{s}^{2} \mathrm{rms}$ at $315 \mathrm{~Hz}$. These frequencies and unweighted acceleration magnitudes generate the same frequency-weighted acceleration magnitude of 2.5 $\mathrm{m} / \mathrm{s}^{2} \mathrm{rms}$ according to ISO standard 5349 (7). These vibration levels produced noise levels ranging from 63.5 $\mathrm{dB}(\mathrm{A})$ (for $31.5 \mathrm{~Hz}$ and $63 \mathrm{~Hz}$ ) to $65.7 \mathrm{~dB}(\mathrm{~A})$ (for 315 $\mathrm{Hz}$ ). A preliminary experiment proved that these noise levels did not induce a significant palmar sweating response in the subject. One of these vibration conditions a day, including a control condition of grasping a handle without vibration, was applied to each subject in a randomized order.

The study was performed in November and December.

\section{Statistical methods}

The volume of palmar sweating and the concentration of plasma MHPG were analyzed quantitatively before and during vibration exposure for the six vibration conditions. The percentage increase in palmar sweating caused by vibration was also assessed for the six conditions. A repeated-measures analysis of variance (ANOVA) was used to test the hypothesis of no difference in the palmar sweating response across the six vibration conditions. A P-value of 0.05 was set as the limit of statistical significance.

\section{Results}

Figure 1 presents the mean values of palmar sweating throughout the six vibration conditions. The palmar sweating volume before the vibration exposure did not change significantly across the six vibration conditions. Acute exposure to any vibration stress, including a control condition, caused an increase in the palmar sweating response $(\mathrm{P}<0.0001)$. Although the repeated measures

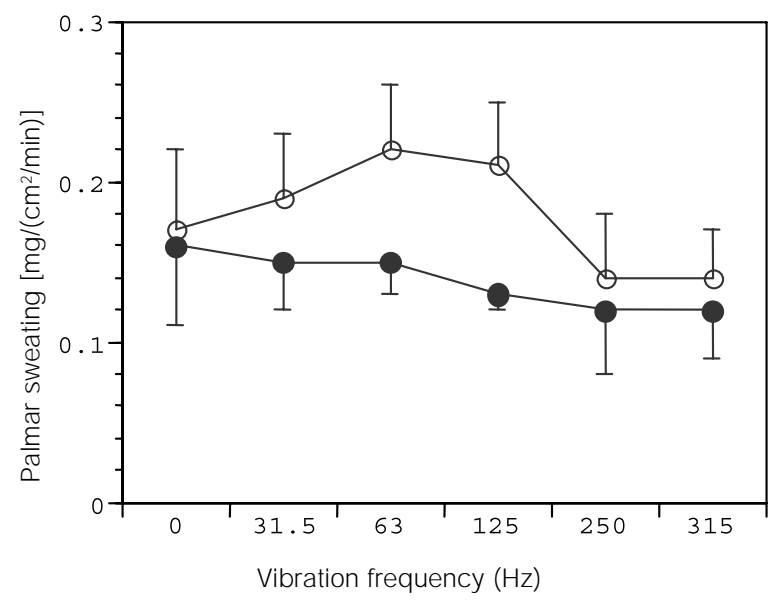

Figure 1. Palmar sweating volumes before and during vibration exposure in six vibration conditions. The values represent the means and standard errors of the means. The filled and unfilled circles show the mean values before and during vibration exposure, respectively. 
ANOVA did not indicate a significant difference among the six vibration conditions $(\mathrm{P}=0.50)$, palmar sweating during vibration frequencies of $63 \mathrm{~Hz}$ and $125 \mathrm{~Hz}$ was the largest with a mean value of $0.22 \mathrm{mg}$ $\left(\mathrm{cm}^{2} / \mathrm{min}\right)$ and $0.21 \mathrm{mg}\left(\mathrm{cm}^{2} / \mathrm{min}\right)$, respectively, followed by $31.5 \mathrm{~Hz}$ with a value of $0.19 \mathrm{mg}\left(\mathrm{cm}^{2} / \mathrm{min}\right)$.

Figure 2 shows the percentage increase in the palmar sweating volume as a result of vibration exposure during the six conditions. Vibration with frequencies of $125 \mathrm{~Hz}$ and $63 \mathrm{~Hz}$ increased the palmar sweating responses by $57.9 \%$ and $50.0 \%$, respectively. Vibration at $250 \mathrm{~Hz}$ and $315 \mathrm{~Hz}$ increased palmar sweating as much as the control of grasping only.

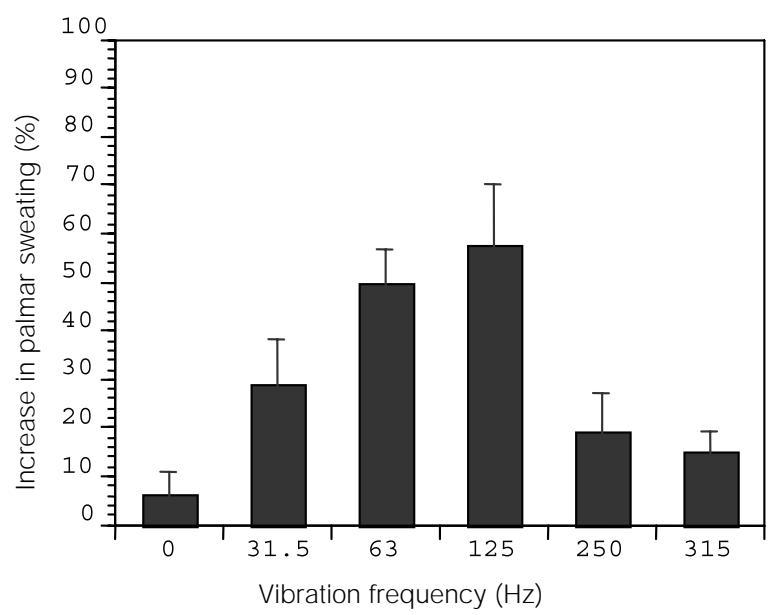

Figure 2. Effects on palmar sweating responseto six vibration frequencies. The values, expressed as the means and the standard errors of the means, represent the percentage of increase in the palmar sweating volumes.

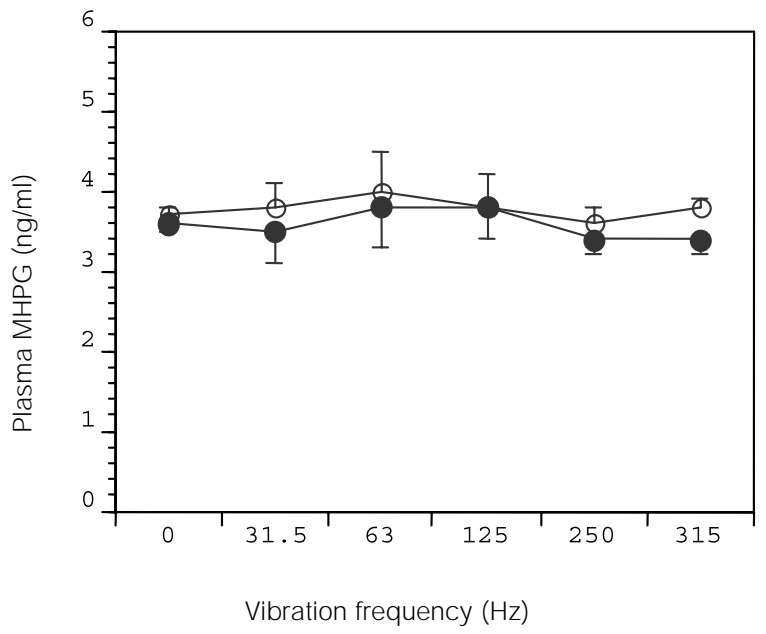

Figure 3. Plasma3-methoxy-4-hydroxyphenylglycol (MHPG) concentrations before and immediately after six vibration exposures. The values represent the means and standard errors of the means. The filled and unfilled circles show the mean values before and after vibration exposure, respectively.
Figure 3 indicates the plasma MHPG concentration before and immediately after the vibration exposure. The mean values of the MHPG plasma concentration in the six vibration conditions were all within the normal range (3-6 $\mathrm{ng} / \mathrm{ml}$ ) for healthy male subjects. The plasma MHPG concentration before the vibration exposure did not change significantly across the six vibration conditions or during any vibration exposure. Nor did vibration exposure cause a significant increase in the plasma MHPG concentration.

\section{Discussion}

According to international standard ISO 5349, frequency weighting is to be used for the assessment of all biological effects of hand-arm vibration (7). In this context, the vibration conditions used in our study can be considered to have the same frequency-weighted acceleration magnitude of $2.5 \mathrm{~m} / \mathrm{s}^{2} \mathrm{rms}$. In our study, therefore, we evaluated the effects of different vibration frequencies with the same frequencyweighted acceleration magnitude on palmar sweating response.

Some studies have shown that the vascular response to vibration stress depends upon the vibration frequency $(8,9)$. In a study $(4)$ in which the effect of vibration frequency on vascular response to vibration exposure was observed in the contralateral finger vibration frequency of $63-250 \mathrm{~Hz}$ provoked a significantly large response, and the central sympathetic vasomotor reflex elicited by the pacinian corpuscles was suggested to be a possible mechanism for the response. A similar phenomenon was observed for palmar sweating response.

We have earlier shown that vibration at $125 \mathrm{~Hz}$ with a magnitude of $50 \mathrm{~m} / \mathrm{s}^{2} \mathrm{rms}$, unweighted (equivalent to $6.25 \mathrm{~m} / \mathrm{s}^{2} \mathrm{rms}$ weighted), induces palmar sweating response to vibration exposure in the contralateral side (5). In our present study, on the other hand, we observed that even a smaller magnitude of vibration produces a palmar sweating response.

With the same weighted acceleration magnitude, exposure to $125 \mathrm{~Hz}$ vibration produced the largest palmar sweating response, followed by $63 \mathrm{~Hz}$ and $31.5 \mathrm{~Hz}$, although no significant change was obtained. Vibration at $315 \mathrm{~Hz}$ only increased palmar sweating as much as grasping. This finding suggests that the palmar sweating response to hand-arm vibration depends upon the vibration frequency.

Two mechanisms are known for vibration to induce palmar sweating, excitation of the higher center of the sympathetic nervous system (10) and the somatosympathetic reflex (11). As we previously observed (5), vibration intensity expressed as acceleration magnitude 
seems to be associated with the former mechanism for palmar sweating response. The greater the vibration, the more discomfort produced in the subject, the result being excitation of the hypothalamus. With the same frequency-weighted acceleration magnitude, on the other hand, vibration frequency can be considered to affect the palmar sweating response through the somatosympathetic reflex. Pacinian corpuscles are vibration receptors activated in frequencies above $60 \mathrm{~Hz}$, and they are the most sensitive at $125 \mathrm{~Hz}$ (12). This fact is compatible with our result that exposure to vibration at both 63 $\mathrm{Hz}$ and $125 \mathrm{~Hz}$ increased palmar sweating to the greatest degree. The higher the vibration frequency, the larger the input as total vibration stress to the body, the result being an increase in palmar sweating. As observed in our study, however, vibration at frequencies above 250 $\mathrm{Hz}$ produces total vibration stress that is too weak to produce palmar sweating. The palmar sweating response to vibration stress seems to depend on its frequency in a certain range, with which the optimal frequency range of pacinian corpuscles is consistent. Further study is needed with a larger number of subjects to provide more information on the frequency dependence of vibration on the palmar sweating response.

MHPG is known as a major metabolite of norepinephrine in the human brain (13). According to Maas et al (6), estimates of the concentration of MHPG in plasma could provide a possible reflection of the activity of noradrenergic neurons in the brain. In our present study, MHPG did not increase significantly across the six vibration exposures; this finding suggests that vibration with frequency-weighted acceleration of $2.5 \mathrm{~m} / \mathrm{s}^{2} \mathrm{rms}$ did not activate the central noradrenergic neurons to such an extent that the subject felt discomfort. This finding indicates the possibility that the different palmar sweating responses to the six vibration frequencies used in this study are responsible for the somatosympathetic reflex rather than the mechanism related to the hypothalamus.

In conclusion, the palmar sweating response to vibration suggests dependency on vibration frequency. The different palmar sweating responses to vibration frequencies suggest a contribution by the somatosympathetic reflex via pacinian corpuscles.

\section{References}

1. Egan CE, Espies BH, McKenna KM, Allen JA. Acute effects of vibration on peripheral blood flow in healthy subjects. Occup Environ Med 1996;53:663-9.

2. Sakakibara H, Kondo T, Koike Y, Miyao M, Furuta M, Yamada $\mathrm{S}$, et al. Combined effects of vibration and noise on palmar sweating. Eur J Appl Physiol 1989;59:195-8.

3. Bovenzi M, Lindsell CJ, Griffin MJ. Magnitude of acute exposures to vibration and finger circulation. Scand J Work Environ Health 1999;25:278-84.

4. Bovenzi M, Lindsell CJ, Griffin MJ. Acute vascular responses to the frequency of vibration transmitted to the hand. Occup Environ Med 2000;57:422-30.

5. Ando H, Ishitake T, Miyazaki Y, Kano M, Tsutsumi A, Matoba T. The mechanism of a human reaction to vibration stress by palmar sweating in relation to autonomic nerve tone. Int Arch Occup Environ Health 2000;73:41-6.

6. Maas JW, Hattox SE, Landis DH, Roth RH. The determination of a brain arteriovenous difference for 3-methoxy-4hydroxyphenethyleneglycol (MHPG). Brain Res 1976;118: 167-73.

7. International Organization for Standardization (ISO). Mechanical vibration - measurement and assessment of human exposure to hand-transmitted vibration - part 1: general guidelines: Geneva: ISO, 1997. ISO/CD 5349-1.

8. Hyvärinen J, Pyykkö I, Sundberg S. Vibration frequencies and amplitudes in the aetiology of traumatic vasospastic disease. Lancet 1973;1:791-4.

9. Furuta M, Sakakibara H, Miyao M, Kondo T, Yamada S. Effect of vibration frequency on finger blood flow. Int Arch Occup Environ Health 1991;63:221-4.

10. Matoba T, Chiba M, Sakurai T. Body reactions during chain saw work. Br J Ind Med 1985;42:667-71.

11. Sato A, Schmidt RF. Somatosympathetic reflexes: afferent fibers, central pathways, discharge characteristics. Physiol Rev 1973;53:916-47.

12. Mountcastle VB, Talbot WH, Darian-Smith I, Kornhuber HH. Neural basis of the sense of flutter-vibration. Science 1967;155:597-600.

13. Goodman Gilman A, Rall T, Nies A, Taylor P. Goodman and Gilman's The pharmacological basis of therapeutics. 8th ed. New York (NY): Macmillan, 1990.

Received for publication: 5 March 2002 